\title{
Antibiotic susceptibility of Staphylococcus aureus with different degrees of biofilm formation
}

Hyo-Jung Shin ${ }^{1 \dagger}$, Sungtae Yang ${ }^{2+}$ and Yong Lim ${ }^{1 *}$

\begin{abstract}
Staphylococcus aureus is one of the most common pathogens in biofilm-associated chronic infections. S. aureus living within biofilms evades the host immune response and is more resistant to antibiotics than planktonic bacteria. In this study, we generated S. aureus with low and high levels of biofilm formation using the rbf (regulator of biofilm formation) gene and performed a BioTimer assay to determine the minimum inhibitory concentration (MIC) and minimal bactericidal concentration (MBC) of various types of antibiotics. We showed that biofilm formation by S. aureus had a greater effect on MBC than MIC, probably due to the different growth modes between planktonic and biofilm bacteria. Importantly, we found that the MBC for biofilm S. aureus was much higher than that for planktonic cells, but there was little difference in MBC between low and high levels of biofilm formation. These results suggest that once the biofilm is formed, the bactericidal activity of antibiotics is significantly reduced, regardless of the degree of $S$. aureus biofilm formation. We propose that $S$. aureus strains with varying degrees of biofilm formation may be useful for evaluating the anti-biofilm activity of antimicrobial agents and understanding antibiotic resistance mechanisms by biofilm development.
\end{abstract}

Keywords: Biofilm formation, Staphylococcus aureus, rbf gene, Antibiotics, Bacterial resistance

\section{Introduction}

A biofilm is a conglomeration of one or more types of microorganisms attached to a surface, in contrast to the planktonic state in which bacteria exist as individual organisms (Flemming et al. 2016; Rumbaugh and Sauer 2020). Biofilm formation not only evades human immunosurveillance, but is also known to limit antibiotic penetration (Gebreyohannes et al. 2019; Koo et al. 2017; Sharma et al. 2019; Verderosa et al. 2019). There is a positive correlation between drug resistance and biofilm development in clinical $S$. aureus isolates (Kwon et al. 2008; Martins et al. 2007). Biofilm-forming bacteria are known to exhibit approximately $100-1000$ times

\footnotetext{
*Correspondence: ylim@chosun.ac.kr

${ }^{\dagger}$ Hyo-Jung Shin and Sungtae Yang have contributed equally to this work

${ }^{1}$ Department of Immunology, Chosun University School of Medicine,

Gwangju 61452, South Korea

Full list of author information is available at the end of the article
}

higher antibiotic resistance than planktonic bacteria (Donlan 2000; Pantanella et al. 2008). The reasons for this are as follows: (1) the penetration of antibiotics into the biofilm is poor; (2) bacteria in the biofilm state are relatively slower in growth and proliferation than those in the planktonic state; (3) biofilms are different from planktonic bacteria in specific metabolic processes; and (4) biofilms appear to facilitate horizontal gene transfer of antibiotic resistance genes (Bjarnsholt et al. 2013; Hall and Mah 2017; Hoiby et al. 2010; Rose and Poppens 2009; Shapiro 1998). Infections caused by biofilm-forming pathogens are difficult to treat using conventional methods and have become a serious problem worldwide (Hall and Mah 2017; Li et al. 2020; Verderosa et al. 2019). For developing therapeutic agents for biofilm-forming bacterial infections, the susceptibility of antibiotics should be tested under biofilm conditions rather than in the planktonic state. Bacterial strains with varying degrees 
of biofilm formation are thought to contribute significantly to the search for novel antimicrobial agents effective against chronic biofilm-associated infections and to understand antibiotic resistance mechanisms due to biofilm development.

Staphylococcus aureus, a major cause of communityacquired infections and nosocomial infections, can form biofilms on the surfaces of various medical devices used in hospitals, leading to chronic and persistent infections (Ando et al. 2004; Baltch et al. 2008; Cirz et al. 2007; Villain-Guillot et al. 2007). Treatment of S. aureus biofilmassociated infections is very limited because of reduced antibiotic susceptibility. One of the most significant problems with biofilm formation by $S$. aureus is the development of resistance to antibiotics (Kranjec et al. 2021; Lin et al. 2019). Although the mechanism of $S$. aureus biofilm formation remains unclear, it is believed that bacteria deposit on solid surfaces, accumulate multi-layered cell clusters, and then evolve into mature biofilms, as illustrated in Fig. 1 (Moormeier and Bayles 2017; Otto 2013). We previously found that the $r b f$ (regulator of biofilm formation) gene contributes significantly to biofilm formation by $S$. aureus on polystyrene or glass by interfering with the multicellular aggregation step without affecting the initial stage of biofilm formation (Lim et al. 2004). The $r b f$ gene is also known to play an important role in biofilm formation in vivo (Luong et al. 2009). Therefore, different degrees of $S$. aureus biofilm formation can be generated by targeting the $r b f$ gene.

In this study, we prepared a $r b f$-inactivated strain (CYL1135) and a rbf-complemented strain (CYL1106) of S. aureus with low and high degrees of biofilm formation, respectively, and investigated the antimicrobial activities of various antibiotics against planktonic and biofilm $S$. aureus in vitro. Additionally, we evaluated the ability of the antibiotics to detach the biofilm matrix using a high biofilm-forming CYL1106 strain. We believe that $S$. aureus with different degrees of biofilm formation could be useful for the discovery of novel antibiotics and substances that can effectively inhibit and/or eliminate biofilm formation.

\section{Methods \\ Materials}

The antibiotics used in this study were as follows: bacampicillin, moxifloxacin, norfloxacin, and amoxicillin-clavulanate from Chong Kun Dang Bio Co. (Seoul, Korea); ciprofloxacin, cefaclor, and amikacin from Ildong Pharm. Co. (Seoul, Korea); cefotaxime and quinupristin-dalfopristin from Handok Pharm. Co. (Seoul, Korea); ampicillin-sulbactam and ceftriaxone from Hanmi Pharm. Co. (Seoul, Korea); kanamycin from Donga Pharm. Co. (Seoul, Korea); tobramycin from Daewoong Pharm. Co. (Seoul, Korea); vancomycin from Cheiljedang Co. (Seoul, Korea); teicoplanin from SanofiAventis Korea Co. (Seoul, Korea); erythromycin from Fluka Biochemika (Buchs, Switzerland); and fosfomycin from Pharmbio Korea Co. (Seoul, Korea). Antibiotics were of analytical grade.

\section{Preparation of S. aureus with different degrees of biofilm formation}

CYL1135, in which the rbf gene of S. aureus was inactivated, whereas CYL1106, in which the rbf gene was complemented with a multicopy plasmid, was generated as described previously (Kwon et al. 2013; Lim et al. 2004). Briefly, an internal fragment of the $r b f$ gene (724 base pairs) from the 8325-4 strain was amplified by polymerase chain reaction (PCR) with two primers $5^{\prime}$-CACTCA TAAAAGCTTCTTC- $3^{\prime}$ and $5^{\prime}$-TGGTGATTTGCGAGA

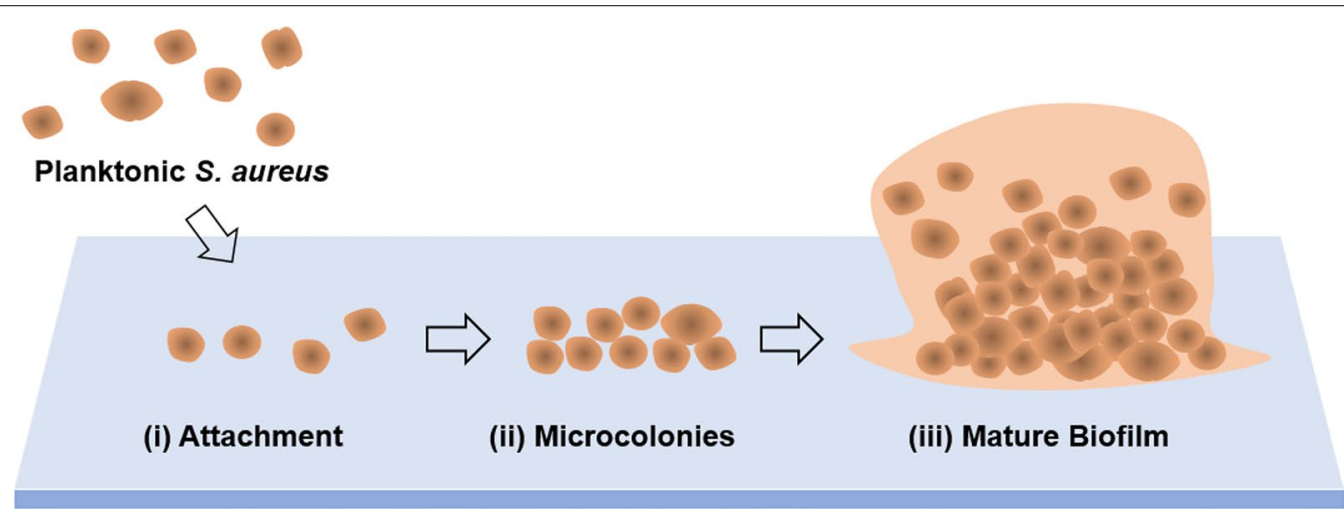

Fig. 1 Model of S. aureus biofilm development: (1) During the attachment phase, planktonic S. aureus adheres to a biotic surface and forms a monolayer. (2) After the attachment is accomplished, microcolonies are formed with multilayering cells. (3) The microcolonies evolve into a mature biofilm 
TGAGCV-3', and then cloned into pCL53. The resulting pYL8564 plasmid was transformed into the tetracycline resistant RN4220 strain and verified by PCR.

\section{Antibiotics susceptibility test on planktonic S. aureus}

Minimal inhibitory concentrations (MICs) and minimal bactericidal concentrations (MBCs) of antibiotics were determined following the microdilution procedure of the Clinical and Laboratory Standard Institute (CLSI) guidelines. In brief, CYL1135 strains were inoculated into Mueller Hinton broth (MHB) medium (Becton Dickinson, NJ, USA), cultured in a $37{ }^{\circ} \mathrm{C}$ shaking incubator for $24 \mathrm{~h}$, and diluted with MHB to a bacterial count of $5 \times 10^{5} \mathrm{CFU} \mathrm{ml}{ }^{-1}$. Samples were prepared for serial twofold dilutions in equivalent volumes for various concentrations of antibiotics distributed on the microplates. The plates were incubated overnight at $37^{\circ} \mathrm{C}$ in an incubator, and the absorbance was measured at $620 \mathrm{~nm}$. The minimum concentration at which the bacteria did not grow by more than $90 \%$ was determined as the MIC. To measure MBCs, the culture medium in which the bacteria did not grow was transferred to a tryptic soy agar (TSA) plate and then cultured overnight at $37^{\circ} \mathrm{C}$. The minimum concentration at which bacteria did not completely grow in the TSA medium was defined as the MBC.

\section{Antibiotics susceptibility test on biofilm S. aureus}

To measure the MIC in biofilm bacteria, a modification of the existing Bio-Timer assay (BTA) was performed as previously described (Pantanella et al. 2008). In brief, CYL1135 and CYL1106 strains were inoculated into tryptic soy broth (TSB) medium (Becton Dickinson, NJ, USA) containing $0.25 \%$ glucose and cultured overnight at $37{ }^{\circ} \mathrm{C}$ in a shaking incubator. After measuring the optical density at $600 \mathrm{~nm}\left(\mathrm{OD}_{600}\right)$, the absorbance of the cultured strains was adjusted to 2.5, diluted 5000-fold in TSB medium containing $0.5 \%$ glucose, and then incubated overnight at $37^{\circ} \mathrm{C}$ in a $6 \mathrm{~cm}$ dish (Nunc, Roskilde, Denmark) containing sterilized glass beads (Marienfeld, Lauda-Königshofen, Germany). The culture medium was rinsed twice with sterilized phosphate-buffered saline (PBS) at $6.5 \mathrm{rpm}$ for $5 \mathrm{~min}$. A glass bead containing biofilm was placed in each well of a 24-well plate containing $1 \mathrm{ml}$ of diluted antibiotics at a maximum of $1024 \mu \mathrm{g} \mathrm{ml}^{-1}$ in the BioTimer-phenol red (BT-PR) medium. As a positive control, a glass bead containing biofilm was placed in a BT-PR medium without antibiotics. Sterilized glass beads in BT-PR medium were used as a negative control. The number of biofilm-forming strains was approximately $5 \times 10^{5} \mathrm{CFU} \mathrm{ml}{ }^{-1}$. The concentration of antibiotics in the last well (red color) was defined as the MIC of biofilm bacteria. To measure MBC in the biofilm state, beads were taken from each well of the MIC plate where bacteria did not grow, transferred to a new 24-well plate containing $1 \mathrm{ml}$ of BT-PR medium, and incubated overnight at $37^{\circ} \mathrm{C}$. The concentration of antibiotics in the last well showing red color was defined as the MBC in biofilm S. aureus.

\section{Biofilm matrix detachment assay}

Overnight cultures with CYL1106 strain were adjusted to an $\mathrm{OD}_{600}$ of 3 and diluted 500-fold in TSB medium supplemented with glucose. Then, a $200 \mu \mathrm{l}$ aliquot of the cell suspension was seeded into each well of a 96-well plate (Costar; Corning Inc., NY, USA). After overnight incubation at $37^{\circ} \mathrm{C}$, each well was gently washed twice with PBS. Antibiotics $(200 \mu \mathrm{l})$ were serially diluted two-fold with TSB medium and incubated for $6 \mathrm{~h}$ at $37^{\circ} \mathrm{C}$. After incubation, the supernatant was discarded, and the cells were rinsed twice with PBS. The plates were dried at room temperature for $1 \mathrm{~h}$ and stained with $0.25 \%$ crystal violet. Absorbance at $590 \mathrm{~nm}$ was measured using a microplate reader (Sunrise ${ }^{\mathrm{TM}}$; Tecan Co., Grödig, Austria).

\section{Results and discussion \\ MICs of several classes of antibiotics against planktonic and biofilm S. aureus}

We first constructed a rbf-inactivated strain (CYL1135) and a rbf-complemented strain (CYL1106) of S. aureus, as described in the Materials and Methods. The ability of CYL1135 and CYL1106 strains to form biofilms was studied using crystal violet staining (Fig. 2A). The CYL1106 strain showed a more than fourfold higher ability to form biofilms than the CYL1135 strain (Fig. 2B). These results demonstrate that the $r b f$ gene is involved in biofilm formation by S. aureus. Therefore, the CYL1135 and CYL1106 strains were used for low and high degrees of biofilm formation by $S$. aureus, respectively. Figure $2 \mathrm{C}$ illustrates the planktonic, low biofilm formation, and high biofilm-forming strains. We then measured the antimicrobial activities of several classes of antibiotics against planktonic and biofilm bacteria. Table 1 shows the MICs of antibiotics in planktonic S. aureus, low biofilm-forming CYL1135, and high biofilm-forming CYL1106 strains. Most antibiotics were more effective against planktonic $S$. aureus than biofilm S. aureus, suggesting that biofilm-forming ability influences antimicrobial resistance (Castano-Arriba et al. 2020; Qi et al. 2016). However, there was no significant difference in MICs between the CYL1135 and CYL1106 strains. The MICs of penicillin-type and quinolone-type antibiotics against planktonic bacteria were 1-4 times lower than those for biofilm bacteria. In contrast, the biofilm-forming strains were 2-16 times more resistant to aminoglycoside-type and glycopeptide antibiotics than planktonic $S$. aureus. Interestingly, moxifloxacin, ceftriaxone, erythromycin, 
(A)

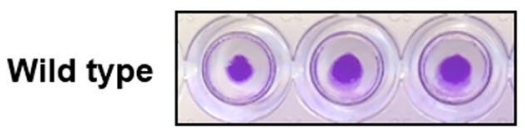

CYL1135

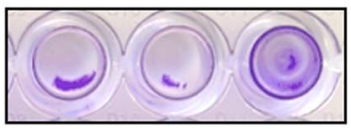

CYL1106

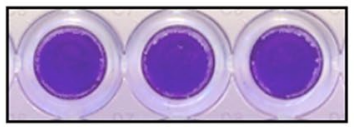

(B)

(C)

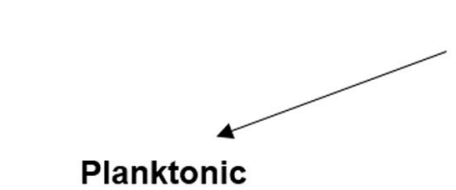

S. aureus

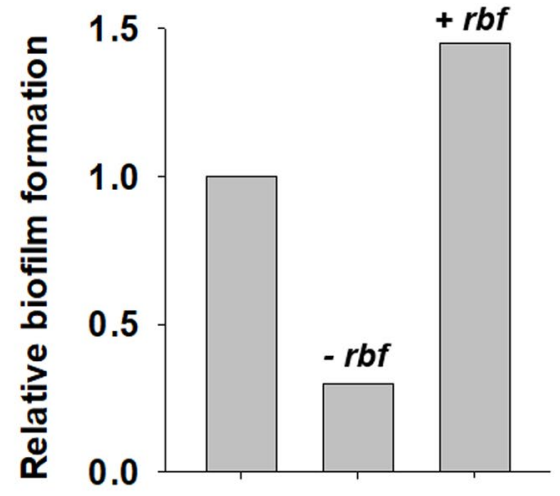

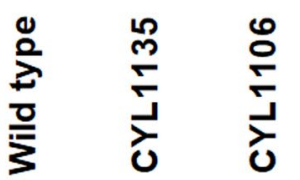
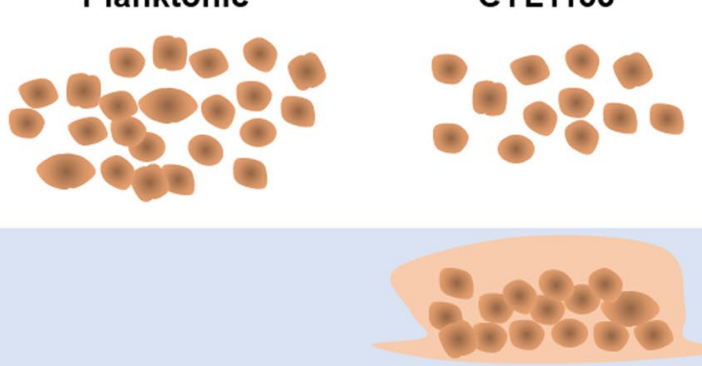

Fig. 2 Effect of the rbf gene on S. aureus biofilm formation.A Wild type, CYL1135, and CYL1106 strains were tested for polystyrene binding in wells of a microtiter plate. The biofilm formed was stained with crystal violet. B Biofilm formation of wild type, CYL1135, and CYL1106. The absorbance was determined at $590 \mathrm{~nm}$. The results represent the averages of three independent experiments. C Schematic representation of planktonic $S$. aureus, low biofilm-forming CYL1135, and high biofilm-forming CYL1106

and quinupristin-dalfopristin showed the same MIC values in planktonic and biofilm states, regardless of the degree of biofilm formation.

\section{MBCs of several classes of antibiotics against planktonic and biofilm S. aureus}

Table 2 shows the MBCs of antibiotics in planktonic and biofilm $S$. aureus strains. The antibiotics used in this study exhibited 2-512 times higher $\mathrm{MBC}$ in the CYL1135 and CYL1106 strains than in planktonic bacteria (Table 2), whereas the MIC difference between planktonic and biofilm S. aureus was 1-64 times (Table 1). The greater decrease in bactericidal than bacteriostatic capacity is probably due to the different growth modes between planktonic and biofilm $S$. aureus. Among the antibiotics used in the experiment, moxifloxacin, amikacin, tobramycin, and quinupristin-dalfopristin showed the lowest increase rate in $\mathrm{MBC}$ in biofilm cells compared to planktonic cells, indicating that they are effective bactericidal antibiotics under biofilm conditions. Some antibiotics in the same class showed different antimicrobial activity against $S$. aureus. For example, among the fluoroquinolones, moxifloxacin was more effective in killing $S$. aureus than ciprofloxacin, supporting the view that moxifloxacin has enhanced activity against grampositive bacteria compared to ciprofloxacin (Zhanel et al. 2002). Interestingly, given the difference in MBC between planktonic and biofilm $S$. aureus, there was no significant 
Table 1 Minimum inhibitory concentrations (MICs) of antibiotics in planktonic S. aureus, low biofilm-forming CYL1135, and high biofilm-forming CYL1106 strains

\begin{tabular}{|c|c|c|c|}
\hline \multirow[t]{2}{*}{ Antimicrobial agents } & \multicolumn{3}{|c|}{ MIC $\left(\mu \mathrm{g} \mathrm{ml}^{-1}\right)$} \\
\hline & Planktonic & CYL1135 & CYL1106 \\
\hline \multicolumn{4}{|l|}{ Penicillins } \\
\hline Bacampicillin & 0.25 & 0.5 & 0.5 \\
\hline Amoxicillin-clavulanate & 0.5 & 1 & 1 \\
\hline Ampicillin-sulbactam & 1 & 2 & 2 \\
\hline \multicolumn{4}{|l|}{ Quinolones } \\
\hline Ciprofloxacin & 0.125 & 0.5 & 0.5 \\
\hline Norfloxacin & 0.5 & 1 & 1 \\
\hline Moxifloxacin & 0.06 & 0.06 & 0.06 \\
\hline \multicolumn{4}{|l|}{ Cephalosporins } \\
\hline Cefaclor & 1 & 4 & 8 \\
\hline Cefotaxime & 0.5 & 1 & 2 \\
\hline Ceftriaxone & 2 & 2 & 2 \\
\hline \multicolumn{4}{|l|}{ Aminoglycosides } \\
\hline Amikacin & 2 & 8 & 16 \\
\hline Kanamycin & 1 & 16 & 16 \\
\hline Tobramycin & 0.5 & 2 & 2 \\
\hline \multicolumn{4}{|l|}{ Glycopeptides } \\
\hline Teicoplanin & 0.125 & 0.25 & 1 \\
\hline Vancomycin & 0.5 & 1 & 2 \\
\hline \multicolumn{4}{|l|}{ Others } \\
\hline Erythromycin & 0.25 & 0.25 & 0.25 \\
\hline Fosfomycin & 2 & 64 & 128 \\
\hline Quinupristin-dalfopristin & 0.125 & 0.125 & 0.125 \\
\hline
\end{tabular}

difference in MBC between the CYL1135 and CYL1106 strains. These results suggest that once the biofilm is formed, it is difficult to kill S. aureus, regardless of the degree of biofilm formation.

\section{Effect of antibiotics on biofilm detachment of CYL1135 cells}

Next, we measured the detachment effect of antibiotics on the biofilm matrix of S. aureus (Fig. 3). Biofilms grown with the high biofilm-forming CYL1106 strain were incubated with antibiotics. Among the antibiotics of each class used in the experiment, those with the lowest difference in $\mathrm{MBC}$ between planktonic and biofilm cells were selected: (A) bacampicillin, (B) moxifloxacin, (C) cefotaxime, (D) tobramycin, (E) teicoplanin, and (F) erythromycin. Moxifloxacin, tobramycin, and teicoplanin showed little biofilm degradation at concentrations below $8 \mu \mathrm{g} \mathrm{ml}^{-1}$. However, cefotaxime, bacampicillin, and erythromycin at concentrations above $2 \mu \mathrm{g} \mathrm{ml}^{-1}$ led to a $40-50 \%$ removal of the biofilm. Considering that there is a close correlation between drug resistance and biofilm development, the high
Table 2 Minimum bactericidal concentrations (MBCs) of antibiotics in planktonic S. aureus, low biofilm-forming CYL1135, and high biofilm-forming CYL1106 strains

\begin{tabular}{|c|c|c|c|}
\hline \multirow[t]{2}{*}{ Antimicrobial agents } & \multicolumn{3}{|c|}{$M B C\left(\mu \mathrm{g} \mathrm{ml}^{-1}\right)$} \\
\hline & Planktonic & CYL1135 & CYL1106 \\
\hline \multicolumn{4}{|l|}{ Penicillins } \\
\hline Bacampicillin & 0.25 & 8 & 16 \\
\hline Amoxicillin-clavulanate & 0.5 & 16 & 64 \\
\hline Ampicillin-sulbactam & 1 & 64 & 64 \\
\hline \multicolumn{4}{|l|}{ Quinolones } \\
\hline Ciprofloxacin & 0.125 & 4 & 4 \\
\hline Norfloxacin & 0.5 & 1 & 16 \\
\hline Moxifloxacin & 0.06 & 0.125 & 0.5 \\
\hline \multicolumn{4}{|l|}{ Cephalosporins } \\
\hline Cefaclor & 1 & 128 & 512 \\
\hline Cefotaxime & 0.5 & 32 & 64 \\
\hline Ceftriaxone & 2 & 128 & 128 \\
\hline \multicolumn{4}{|l|}{ Aminoglycosides } \\
\hline Amikacin & 2 & 16 & 16 \\
\hline Kanamycin & 1 & 16 & 64 \\
\hline Tobramycin & 0.5 & 4 & 4 \\
\hline \multicolumn{4}{|l|}{ Glycopeptides } \\
\hline Teicoplanin & 0.125 & 2 & 4 \\
\hline Vancomycin & 0.5 & 4 & 16 \\
\hline \multicolumn{4}{|l|}{ Others } \\
\hline Erythromycin & 0.25 & 4 & 8 \\
\hline Fosfomycin & 16 & 128 & 1024 \\
\hline Quinupristin-dalfopristin & 0.125 & 0.5 & 1 \\
\hline
\end{tabular}

biofilm-forming CYL1135 strain could be very useful for understanding biofilm mechanisms or screening novel antibiotics to eradicate biofilms.

\section{Conclusions}

Pathogenic biofilm formation is recognized as a major challenge in treating many persistent infections (Gebreyohannes et al. 2019). Susceptibility testing of planktonic bacteria can be an impediment to the successful treatment of chronic infections caused by biofilm-forming pathogens. In this study, we generated S. aureus with different degrees of biofilm formation and measured the MICs and MBCs for low and high biofilm-forming strains. Most importantly, we found a large difference in $\mathrm{MBC}$ between the planktonic and biofilm states, but the difference in $\mathrm{MBC}$ between low and high levels of biofilm formation was insignificant. We propose that once the biofilm is formed, the bactericidal activity of antibiotics is significantly reduced, regardless of the degree of biofilm formation by $S$. aureus. 
(A)

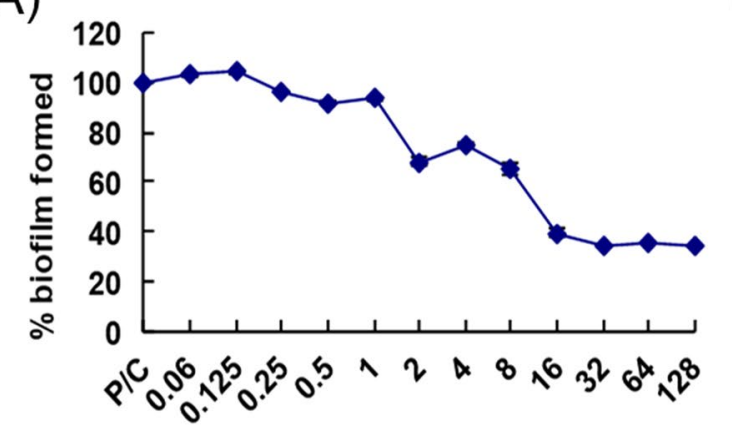

(C)

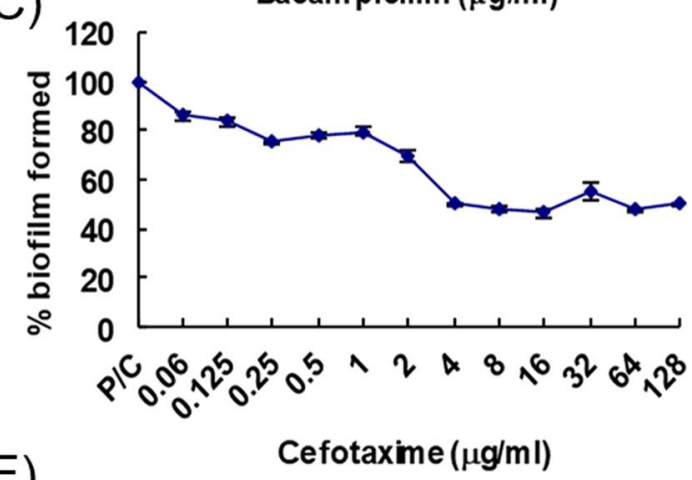

(E)

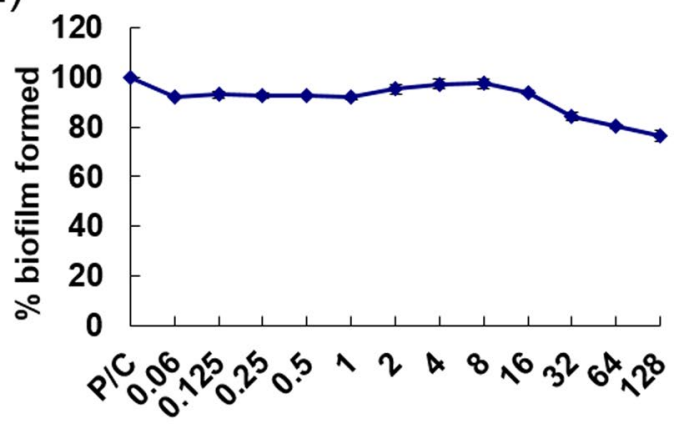

Teicoplanin $(\mu \mathrm{g} / \mathrm{ml})$
(B)

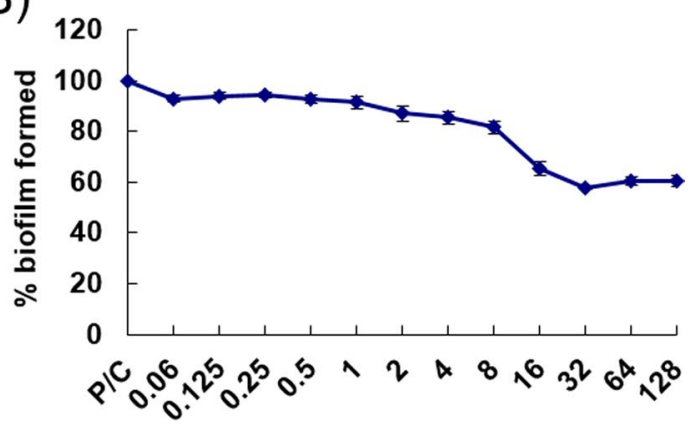

(D)

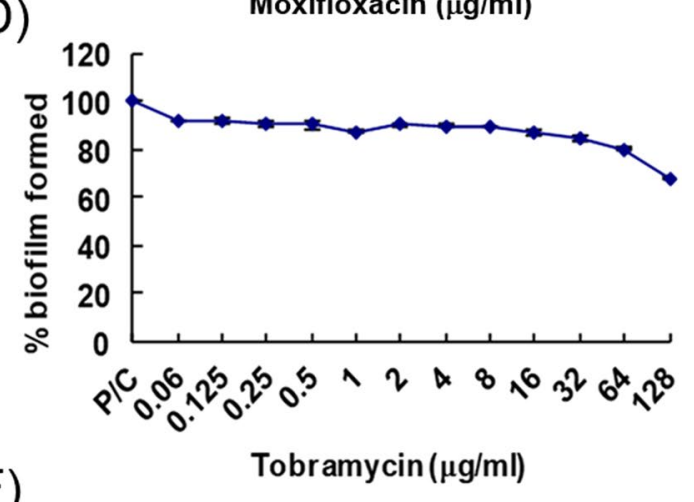

(F)

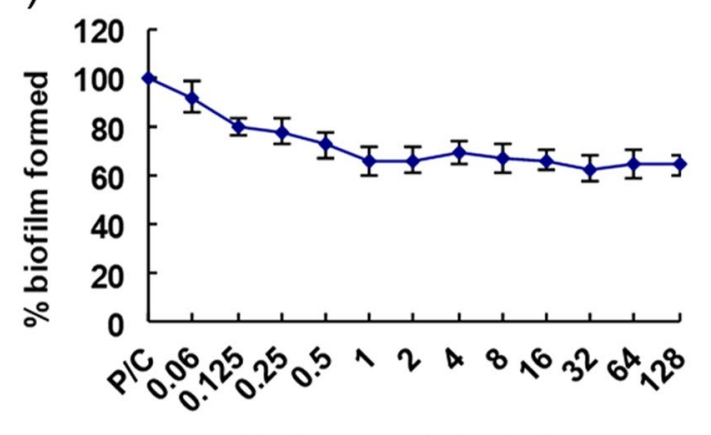

Erythromycin $(\mu \mathrm{g} / \mathrm{ml})$

Fig. 3 Biofilm detachment for CYL1106 strains in the presence of the antibiotics. Antibiotic with the lowest difference in MBCs between planktonic and CYL1 106 strains was selected: $\mathbf{A}$ bacampicillin, B moxifloxacin, C cefotaxime, D tobramycin, E teicoplanin, and $\mathbf{F}$ erythromycin

\section{Abbreviations}

MIC: Minimum inhibitory concentration; MBC: Minimum bactericidal concentration; rbf: Regulator of biofilm formation; PCR: Polymerase chain reaction;

BTA: BioTimer assay; BT-PR: BioTimer-phenol red; TSA: Tryptic soy agar; TSB: Tryptic soy broth; PBS: Phosphate-buffered saline; MHB: Mueller Hinton broth; CFU: Colony forming unit.

Acknowledgements

Not applicable.

\section{Authors' contributions}

HS performed most of the experiments. All authors designed the research, analyzed the data, and wrote the manuscript. All authors read and approved the final manuscript.

\section{Funding}

Not applicable.
Availability of data and materials

Not applicable.

\section{Declarations}

Competing interests

The authors declare that they have no competing interests.

\section{Author details}

${ }^{1}$ Department of Immunology, Chosun University School of Medicine, Gwangju 61452, South Korea. '2Department of Microbiology, Chosun University School of Medicine, Gwangju 61452, South Korea.

Received: 27 July 2021 Accepted: 15 September 2021

Published online: 24 September 2021 


\section{References}

Ando E, Monden K, Mitsuhata R, Kariyama R, Kumon H. Biofilm formation among methicillin-resistant Staphylococcus aureus isolates from patients with urinary tract infection. Acta Med Okayama. 2004;58:207-14.

Baltch AL, Ritz WJ, Bopp LH, Michelsen P, Smith RP. Activities of daptomycin and comparative antimicrobials, singly and in combination, against extracellular and intracellular Staphylococcus aureus and its stable smallcolony variant in human monocyte-derived macrophages and in broth. Antimicrob Agents Chemother. 2008:52:1829-33.

Bjarnsholt T, Ciofu O, Molin S, Givskov M, Hoiby N. Applying insights from biofilm biology to drug development-can a new approach be developed? Nat Rev Drug Discov. 2013;12:791-808.

Castano-Arriba A, Gonzalez-Machado C, Igrejas G, Poeta P, Alonso-Calleja C, Capita R. Antibiotic resistance and biofilm-forming ability in enterococcal isolates from red meat and poultry preparations. Pathogens. 2020;9:1021.

Cirz RT, Jones MB, Gingles NA, Minogue TD, Jarrahi B, Peterson SN, Romesberg FE. Complete and SOS-mediated response of Staphylococcus aureus to the antibiotic ciprofloxacin. J Bacteriol. 2007;189:531-9.

Donlan RM. Role of biofilms in antimicrobial resistance. ASAIO J. 2000:46:S47-52.

Flemming HC, Wingender J, Szewzyk U, Steinberg P, Rice SA, Kjelleberg S. Biofilms: an emergent form of bacterial life. Nat Rev Microbiol. 2016;14:563-75.

Gebreyohannes G, Nyerere A, Bii C, Sbhatu DB. Challenges of intervention, treatment, and antibiotic resistance of biofilm-forming microorganisms. Heliyon. 2019;5:e02192.

Hall CW, Mah TF. Molecular mechanisms of biofilm-based antibiotic resistance and tolerance in pathogenic bacteria. FEMS Microbiol Rev. 2017;41:276-301.

Hoiby N, Bjarnsholt T, Givskov M, Molin S, Ciofu O. Antibiotic resistance of bacterial biofilms. Int J Antimicrob Agents. 2010;35:322-32.

Koo H, Allan RN, Howlin RP, Stoodley P, Hall-Stoodley L. Targeting microbial biofilms: current and prospective therapeutic strategies. Nat Rev Microbiol. 2017;15:740-55.

Kranjec C, Morales Angeles D, Torrissen Marli M, Fernandez L, Garcia P, Kjos M, Diep DB. Staphylococcal biofilms: challenges and novel therapeutic perspectives. Antibiotics (basel). 2021;10:131

Kwon AS, Park GC, Ryu SY, Lim DH, Lim DY, Choi CH, Park Y, Lim Y. Higher biofilm formation in multidrug-resistant clinical isolates of Staphylococcus aureus. Int J Antimicrob Agents. 2008;32:68-72.

Kwon AS, Lim DH, Shin HJ, Park G, Reu JH, Park HJ, Kim J, Lim Y. The N3 subdomain in a domain of fibronectin-binding protein B isotype I is an independent risk determinant predictive for biofilm formation of Staphylococcus aureus clinical isolates. J Microbiol. 2013:51:499-505.

Li Y, Xiao P, Wang Y, Hao Y. Mechanisms and control measures of mature biofilm resistance to antimicrobial agents in the clinical context. ACS Omega. 2020;5:22684-90.
Lim Y, Jana M, Luong TT, Lee CY. Control of glucose- and NaCl-induced biofilm formation by rbf in Staphylococcus aureus. J Bacteriol. 2004;186:722-9.

Lin Q, Sun H, Yao K, Cai J, Ren Y, Chi Y. The prevalence, antibiotic resistance and biofilm formation of Staphylococcus aureus in bulk ready-to-eat foods. Biomolecules. 2019:9:524.

Luong TT, Lei MG, Lee CY. Staphylococcus aureus Rbf activates biofilm formation in vitro and promotes virulence in a murine foreign body infection model. Infect Immun. 2009;77:335-40.

Martins A, Couto I, Aagaard L, Martins M, Viveiros M, Kristiansen JE, Amaral L. Prolonged exposure of methicillin-resistant Staphylococcus aureus (MRSA) COL strain to increasing concentrations of oxacillin results in a multidrugresistant phenotype. Int J Antimicrob Agents. 2007;29:302-5.

Moormeier DE, Bayles KW. Staphylococcus aureus biofilm: a complex developmental organism. Mol Microbiol. 2017;104:365-76.

Otto M. Staphylococcal infections: mechanisms of biofilm maturation and detachment as critical determinants of pathogenicity. Annu Rev Med. 2013;64:175-88.

Pantanella F, Valenti P, Frioni A, Natalizi T, Coltella L, Berlutti F. BioTimer Assay, a new method for counting Staphylococcus spp. in biofilm without sample manipulation applied to evaluate antibiotic susceptibility of biofilm. J Microbiol Methods. 2008;75:478-84.

Qi L, Li H, Zhang C, Liang B, Li J, Wang L, Du X, Liu X, Qiu S, Song H. Relationship between antibiotic resistance, biofilm formation, and biofilm-specific resistance in Acinetobacter baumannii. Front Microbiol. 2016;7:483.

Rose WE, Poppens PT. Impact of biofilm on the in vitro activity of vancomycin alone and in combination with tigecycline and rifampicin against Staphylococcus aureus. J Antimicrob Chemother. 2009:63:485-8.

Rumbaugh KP, Sauer K. Biofilm dispersion. Nat Rev Microbiol. 2020;18:571-86.

Shapiro JA. Thinking about bacterial populations as multicellular organisms. Annu Rev Microbiol. 1998;52:81-104.

Sharma D, Misba L, Khan AU. Antibiotics versus biofilm: an emerging battleground in microbial communities. Antimicrob Resist Infect Control. 2019:8:76.

Verderosa AD, Totsika M, Fairfull-Smith KE. Bacterial biofilm eradication agents: a current review. Front Chem. 2019;7:824.

Villain-Guillot P, Gualtieri M, Bastide L, Leonetti JP. In vitro activities of different inhibitors of bacterial transcription against Staphylococcus epidermidis biofilm. Antimicrob Agents Chemother. 2007;51:3117-21.

Zhanel GG, Ennis K, Vercaigne L, Walkty A, Gin AS, Embil J, Smith H, Hoban DJ. A critical review of the fluoroquinolones: focus on respiratory infections. Drugs. 2002;62:13-59.

\section{Publisher's Note}

Springer Nature remains neutral with regard to jurisdictional claims in published maps and institutional affiliations.

\section{Submit your manuscript to a SpringerOpen ${ }^{\circ}$ journal and benefit from:}

- Convenient online submission

- Rigorous peer review

- Open access: articles freely available online

- High visibility within the field

Retaining the copyright to your article

Submit your next manuscript at springeropen.com 